\title{
Long-term safety evaluation of bimatoprost ophthalmic solution $0.03 \%$ : a pooled analysis of six double-masked, randomized, active-controlled clinical trials
}

\author{
This article was published in the following Dove Press journal: \\ Clinical Ophthalmology \\ 6 June 2011 \\ Number of times this article has been viewed
}

\author{
David Wirta' \\ Amanda MVanDenburgh ${ }^{2}$ \\ Emily Weng ${ }^{3}$ \\ Scott MWhitcup ${ }^{4}$ \\ Sef Kurstjens ${ }^{5}$ \\ Frederick C \\ Beddingfield $\mathrm{III}^{4,6}$ \\ 'Private Practice, Newport Beach, \\ CA, USA; ${ }^{2}$ Clinical Development, \\ ${ }^{3}$ Biostatistics, ${ }^{4}$ Research and \\ Development, ${ }^{5} \mathrm{Global}$ Drug \\ Development, Allergan, Inc, Irvine, \\ CA, USA; ${ }^{6}$ Department of Medicine, \\ Division of Dermatology, David \\ Geffen School of Medicine, UCLA, \\ Los Angeles, CA, USA
}

Background: Bimatoprost ophthalmic solution 0.03\% was approved in the US for reducing intraoccular pressure (IOP) based on two double-masked, active-controlled clinical trials. Four additional long-term studies ( $\geq 12$ months) were conducted; however, the aggregate safety profile of the six studies has not been reported.

Methods: Adverse events (AEs) were pooled from six double-masked, active-controlled, longterm clinical trials in which subjects received bimatoprost $0.03 \%$ once daily (QD) or twice daily (BID) as an eyedrop. AE terms were converted to MedDRA (V.11.0) Preferred Terms and analyzed.

Results: In total, 1409 patients received more than one dose of bimatoprost $0.03 \%$ QD or BID. Most AEs were mild in severity and reported by $86.7 \%$ (QD) and $94.8 \%$ (BID) of subjects ( $\leq 12$ months of treatment). AEs reported through month 12 (aggregate incidence of $\geq 5 \%$ ) were conjunctival hyperemia, increased eyelash growth, eye pruritus, periocular skin hyperpigmentation, eye irritation, dry eye, and hypertrichosis. AE onset was generally reported within four months of treatment. The cumulative incidence of common AEs in the QD treatment group at 24-48 months was similar to that measured at 12 months of treatment.

Conclusion: Bimatoprost $0.03 \%$ has a favorable safety and tolerability profile as characterized by six long-term studies. Common AEs were due to the known pharmacological activity of bimatoprost and reversible with treatment cessation.

Keywords: intraocular pressure, eyelids, pharmacology, clinical trial, medical treatment

\section{Introduction}

Bimatoprost is a prostamide, a synthetic prostaglandin structural analog, approved by the US Food and Drug Administration (FDA) in 2001, and is being used worldwide for glaucoma treatment. ${ }^{1}$ Bimatoprost ophthalmic solution $0.03 \%$ (Lumigan ${ }^{\circledR}$, Allergan, Inc, Irvine, CA) exposure has been estimated to be approximately 11.25 million patient-years worldwide, with 6.1 million patient-years in the US alone (data on file, Allergan, Inc). Bimatoprost reduces intraocular pressure (IOP) primarily by increasing aqueous humor outflow via the uveoscleral outflow pathway; bimatoprost also appears to act via the trabecular meshwork. ${ }^{2-5}$ The safety and efficacy of bimatoprost ophthalmic solution $0.03 \%$ administered as an eyedrop for glaucoma treatment has been well studied and repeatedly demonstrated in trials lasting up to 48 months. ${ }^{6-10}$

In December 2008, bimatoprost ophthalmic solution $0.03 \%$ received FDA approval for an additional indication of hypotrichosis of the eyelashes, marketed as Latisse ${ }^{\circledR}$
Correspondence: David Wirta I50I Superior Ave, Suite 303, Newport Beach, CA 92663, USA

$\mathrm{Tel}+$ I 9496501863

Fax +I 9496504359

Email wirtal@hotmail.com 
(bimatoprost $0.03 \%$ ophthalmic solution, Allergan, Inc). It is the first and only FDA-approved treatment to increase eyelash growth, as measured by length, thickness/fullness, and darkness. ${ }^{11}$ The efficacy and safety of bimatoprost ophthalmic solution $0.03 \%$ to enhance eyelash prominence was established in a phase III, multicenter, randomized, double-masked, vehicle-controlled study in which bimatoprost ophthalmic solution $0.03 \%$ was applied to the upper eyelid margins of healthy subjects $(n=278)$ once daily (QD) for up to four months, followed by a one-month treatment-free follow-up period. ${ }^{12}$ The use of bimatoprost in the treatment of eyelash hypotrichosis was recently reviewed elsewhere. ${ }^{13}$

The efficacy of bimatoprost ophthalmic solution $0.03 \%$ was demonstrated by statistically significant improvements in clinician ratings and digital image analysis assessing eyelash length, fullness, and darkness as compared with vehicle; these improvements were sustained during the one-month treatment-free follow-up period. ${ }^{12}$ Findings were supported by statistically significant differences in patient-reported outcomes favoring bimatoprost ophthalmic solution $0.03 \%$ over vehicle, beginning at week 1 and sustained through the treatment and posttreatment follow-up periods. ${ }^{12}$ The incidence of adverse events (AEs) was generally similar between treatment groups; conjunctival hyperemia was the only AE reported in a significantly greater number of subjects receiving bimatoprost ophthalmic solution $0.03 \%(3.6 \%[\mathrm{n}=5])$ than vehicle $(0 \%, P=0.03){ }^{12}$

Because treatment with IOP-lowering medications is expected to be lifelong in most patients, establishing the long-term safety and efficacy of bimatoprost ophthalmic solution $0.03 \%$ is important to the medical community and regulatory authorities. Long-term safety of bimatoprost ophthalmic solution $0.03 \%$ for hypotrichosis is important because its benefit is cosmetic rather than medical. The volume of solution of bimatoprost applied to the upper eyelid is approximately $5 \%$ of that delivered as an eyedrop for glaucoma treatment (Pers comm; Allergan, Inc, 2011). Therefore, a long-term safety analysis from studies of bimatoprost ophthalmic solution $0.03 \%$ QD or twice daily (BID) in glaucoma treatment, which provides a 20-fold (QD administration) to 40-fold (BID administration) increased dosing profile applied to the eye versus bimatoprost ophthalmic solution $0.03 \%$ when applied to the eyelid skin, may be interpolated to support the long-term safety of dermal application for hypotrichosis.

The long-term safety of bimatoprost ophthalmic solution $0.03 \%$ in glaucoma treatment was evaluated in six previously published, double-masked, randomized, active-controlled multicenter clinical trials. ${ }^{6-9,14-17}$ Although summarized individually, the aggregate long-term safety profile of bimatoprost ophthalmic solution $0.03 \%$ as demonstrated in the six clinical studies has not previously been reported, and is of interest with respect to its new indication. Therefore, a pooled analysis of bimatoprost ophthalmic solution $0.03 \%$ safety based on results from the studies was conducted.

\section{Methods}

\section{Study population in long-term glaucoma studies}

This analysis includes pooled individual patient data from six glaucoma clinical trials, conducted from 1998 to 2007, and selected as a representation of the long-term safety profile of bimatoprost ophthalmic solution $0.03 \%$. All studies were masked, randomized, controlled, phase III studies containing at least one treatment group that received bimatoprost ophthalmic solution $0.03 \%$ (without adjunctive therapy), and were at least 12 months in duration. Patients randomized to the bimatoprost ophthalmic solution $0.03 \%$ treatment arms in these studies received one drop QD to both eyes for up to 48 months or one drop BID to both eyes for up to 24 months. Patients in the active comparator groups received either $0.5 \%$ timolol or exploratory bimatoprost formulations; these patients were not included in this analysis and are not described further. All studies had prospectively defined efficacy endpoints, and all based the safety analysis on a tabulation of AE and serious AEs (SAEs). The study population for the pooled analysis comprised all patients $(n=1409)$ who received at least one dose of bimatoprost ophthalmic solution $0.03 \%$ QD or BID as an eyedrop.

\section{Summary of individual studies}

Studies 1 and 2 were randomized, multicenter, double-masked, parallel-group, 12-month phase III studies in which patients received bimatoprost ophthalmic solution $0.03 \%$ QD or BID, or timolol $0.5 \%$ BID. ${ }^{7,8,14}$ Study 3 was a double-masked extension study involving patients enrolled in study 1 or 2 in which patients received bimatoprost ophthalmic solution $0.03 \%$ QD or timolol $0.5 \%$ BID for up to 48 months; patients who had been randomized to BID bimatoprost ophthalmic solution $0.03 \%$ continued this treatment through 24 months and were switched to QD administration through 48 months. ${ }^{69}$ Studies 4 and 5 were randomized, multicenter, double-masked, parallel-group studies in which patients received bimatoprost ophthalmic solution $0.03 \%$ QD, timolol $0.5 \%$ BID, or a fixed combination of bimatoprost ophthalmic solution $0.03 \%$ plus 
timolol 0.5\% QD for three months, followed by a masked extension of nine months. ${ }^{15,16}$ Study 6 was a randomized, multicenter, double-masked, parallel-group study in which patients received bimatoprost $0.03 \%$, bimatoprost $0.01 \%$, or bimatoprost $0.0125 \%$ QD for three months followed by a masked extension of nine months. ${ }^{17}$

All studies were conducted in accordance with applicable institutional review board regulations and in compliance with informed consent regulations and Good Clinical Practice guidelines. ${ }^{6-9,14-17}$ Randomization schedules and sample size calculations have been previously described (Pers comm; Allergan, Inc, 2011)..$^{6-9,14-17}$ Primary and secondary endpoints of the six studies were prospectively defined (Table 1).

Key inclusion criteria for the studies were similar, ie, enrolled patients had primary open-angle glaucoma, chronic closed-angle glaucoma with patent iridotomy, pseudoexfoliative glaucoma, pigmentary glaucoma, or ocular hypertension requiring bilateral treatment, and were either treatment-naive (IOP $\geq 22 \mathrm{mmHg}$ or $24 \mathrm{mmHg}$ at baseline) or had inadequate IOP control (IOP $\geq 18 \mathrm{mmHg}$ in at least one eye) on current therapy. Patients were excluded if they had a contraindication to any study medication, experienced functionally significant visual field loss during the past year, or had filtering surgery within the past six months, or any other intraocular surgery within the past three months. Women who were pregnant, nursing, or of childbearing potential, or were not using reliable birth control were also excluded. ${ }^{6-9,14-17}$ Table 1 summarizes the study designs, number of patients randomized to treatment groups, prospectively defined primary efficacy endpoints, and patient age information for studies 1-6.

\section{Safety analyses}

Briefly, the analysis of demographic, baseline characteristics, and safety data were performed on the safety population, which consists of all subjects who received at least one dose of study medication.

For each AE (regardless of causality) and treatmentrelated AEs, a frequency distribution (numbers, percentages) was tabulated by primary system organ class and preferred terms. Analyses were performed for AEs occurring during the first 12 months or over the entire study period (48 months) by treatment group (bimatoprost QD ophthalmic solution $0.03 \%$ versus bimatoprost BID ophthalmic solution $0.03 \%$ ). Additionally, for subjects involved in the double-blind and open-label extension studies (studies 1, 2, and 3) with treatment exposure up to 48 months, safety analyses were

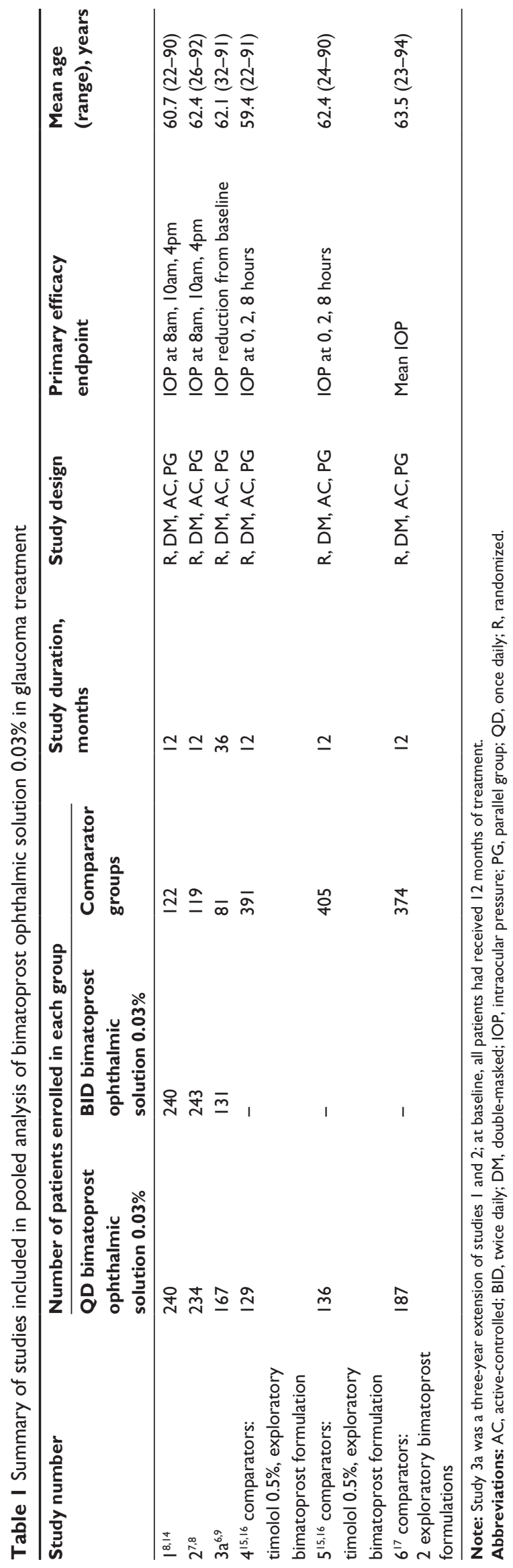


performed for AEs occurring during the first 12 months, 24 months, 36 months, and 48 months.

AE terms from the individual studies were converted to Medical Dictionary for Regulatory Activities (MedDRA) Version 11.0. AEs were calculated based on the total number of patients who were randomized to each treatment group. If more than one episode of an $\mathrm{AE}$ was reported by any individual patient, it was counted only once for the period when it was first reported. Common AEs (incidence of $\geq 5 \%$ for QD bimatoprost ophthalmic solution $0.03 \%$ through the first 12 months) were tabulated; the incidence of each AE was tabulated regardless of causality or relationship to treatment. AE data were also tabulated by demographic subgroup.

\section{Results}

\section{Demographics and treatment exposure}

In the six pooled studies, 1409 patients received at least one dose of bimatoprost ophthalmic solution $0.03 \%$ QD or BID as an eyedrop. The aggregate numbers of patients receiving QD or BID bimatoprost ophthalmic solution $0.03 \%$ at months 4 , $6,12,24,36$, and 48 were $1258,1238,598,153,83$, and 45 , respectively. The median exposure to QD and BID bimatoprost ophthalmic solution $0.03 \%$ was 365 days. As shown in Table 2, the mean age of the study population was 61.5 years and 61.6 years for patients who received at least one dose of bimatoprost ophthalmic solution $0.03 \%$ QD or BID, respectively. In each bimatoprost treatment group, approximately 50\% of patients were female and aged 45-65 years, and $73 \%-77 \%$ were Caucasian. The patients included 356 non-Caucasians and represented approximately $25 \%$ of the study population, providing the ability to evaluate the safety of bimatoprost ophthalmic solution $0.03 \%$ across races.

\section{Long-term AEs at 12 months}

The six pooled studies showed that AEs, regardless of causality, were reported by $86.7 \%$ and $94.8 \%$ of patients receiving up to 12 months of treatment with either QD or BID bimatoprost ophthalmic solution $0.03 \%$, respectively. Most AEs were mild in severity. The most commonly reported AE through month 12 (incidence of $\geq 5 \%$ among patients receiving QD bimatoprost ophthalmic solution $0.03 \%$ ) are summarized in Table 3 . Common AEs included conjunctival hyperemia, growth of eyelashes, eye pruritus, skin hyperpigmentation, eye irritation, dry eye, and hypertrichosis. The incidence of these AEs was higher in the BID bimatoprost ophthalmic solution $0.03 \%$ group than in the QD group.
Table 2 Patient demographics in the pooled long-term glaucoma studies

\begin{tabular}{lll}
\hline Characteristic & $\begin{array}{l}\text { QD bimatoprost } \\
\text { ophthalmic } \\
\text { solution } \mathbf{0 . 0 3} \% \\
(\mathbf{n}=\mathbf{9 2 6})\end{array}$ & $\begin{array}{l}\text { BID bimatoprost } \\
\text { ophthalmic } \\
\text { solution } \mathbf{0 . 0 3} \% \\
(\mathbf{n}=\mathbf{4 8 3})\end{array}$ \\
\hline Age, years & & \\
Mean \pm standard deviation & $61.5 \pm 12.3$ & $61.6 \pm 12.0$ \\
Median & 63.0 & 63.0 \\
Minimum, maximum & 22,94 & 32,91 \\
Age distribution, \% & & \\
<45 years & 9.0 & 9.5 \\
45-65 years & 50.0 & 47.6 \\
$>65$ years & 41.0 & 42.9 \\
Gender, \% & & \\
Male & 46.2 & 48.4 \\
Female & 53.8 & 51.6 \\
Race, \% & & \\
Caucasian & 73.7 & 76.8 \\
Black & 16.8 & 17.0 \\
Asian & 1.4 & 2.7 \\
Hispanic & 7.7 & 3.1 \\
Other & 0.4 & 0.4 \\
\hline
\end{tabular}

Abbreviations: BID, twice daily; QD, once daily.

\section{Study/treatment discontinuations due to AEs}

Among the 1409 patients treated with bimatoprost, 220 subjects (110 for each treatment group) discontinued study treatment before the end of the studies due to AEs. Most AEs leading to study or treatment discontinuation (conjunctival hyperemia, growth of eyelashes, eye pruritus, skin hyperpigmentation, eye irritation, dry eye, and hypertrichosis) were ocular in nature, mild in severity, and occurred during the first 12 months $(n=97$ and 99 for patients receiving QD or BID bimatoprost ophthalmic solution $0.03 \%$ ). Conjunctival hyperemia was the AE mostly

Table 3 Common AEs ( $\geq 5 \%$ ) reported through month 12 in the six pooled long-term glaucoma studies

\begin{tabular}{lll}
\hline AE & \multicolumn{2}{l}{ Incidence of AEs (\%) } \\
\cline { 2 - 3 } & $\begin{array}{l}\text { QD bimatoprost } \\
\text { ophthalmic } \\
\text { solution } \mathbf{0 . 0 3 \%}\end{array}$ & $\begin{array}{l}\text { BID bimatoprost } \\
\text { ophthalmic } \\
\text { solution 0.03\% } \\
(\mathbf{n}=\mathbf{9 2 6})\end{array}$ \\
\hline Conjunctival hyperemia & 43.7 & 56.5 \\
Growth of eyelashes & 20.3 & 45.5 \\
Eye pruritus & 10.7 & 16.1 \\
Skin hyperpigmentation & 6.5 & 11.8 \\
Eye irritation & 5.8 & 8.3 \\
Dry eye & 5.2 & 10.1 \\
Hypertrichosis & 5.1 & 9.1 \\
\hline
\end{tabular}

Abbreviations: AEs, adverse events; BID, twice daily; QD, once daily. 
associated with early discontinuation from the studies, leading to discontinuation of 37 (4.0\%, all occurring during the first 12 months) and 43 (8.7\% during the first 12 months and $0.5 \%$ during more than $12-24$ months) patients receiving QD or BID bimatoprost ophthalmic solution $0.03 \%$, respectively.

\section{SAES}

Most SAEs reported in the pooled studies were nonocular, and were not considered by the investigators to be treatmentrelated. Only one SAE in a timolol comparison study was considered by the investigator to be related to study treatment, ie, chest pain. SAEs of the eye were reported by two patients in any bimatoprost treatment group (retinal vein occlusion and macular hole, but neither were considered by the investigator to be treatment-related). SAEs were reported by $103(11.1 \%)$ and $51(10.6 \%)$ patients in the QD and BID bimatoprost ophthalmic solution $0.03 \%$ groups through the 48 months, respectively (including events that were considered by the investigator to be unrelated to treatment).

\section{Comparisons of SAEs reported at months $4,12,24,36$, and 48}

The cumulative incidence of common SAEs in the QD bimatoprost ophthalmic solution $0.03 \%$ group from three long-term, double-masked, and open-label extension studies at 24, 36, and 48 months was similar to the AE profile after 12 months of treatment (Table 4).

\section{Temporal onset of common AEs}

The temporal onset of common AEs from the pooled studies was also evaluated. As illustrated in Figure 1, for most patients, the reported onset of common AEs was within four months of treatment initiation.

\section{AEs by demographic group}

The incidence of common AEs (Table 4) reported after 12 months of treatment with QD bimatoprost ophthalmic solution $0.03 \%$ was similar across age groups $(<45,45-65$, and $>65$ years) although the rate of conjunctival hyperemia declined with age, from 50.6\% (42/83) in patients aged $<45$ years to $39.2 \%(149 / 380)$ in those aged $>65$ years $(P=0.016)$. In addition, the incidence of common AEs was similar across gender and race.

\section{Discussion}

This pooled analysis of safety data from six long-term studies showed that most AEs reported by patients receiving bimatoprost ophthalmic solution $0.03 \%$ QD or BID as an eyedrop were ocular in nature, mild in severity, and appeared early during treatment. The most common AEs, generally reported at an incidence of $\geq 5 \%$, including conjunctival hyperemia, growth of eyelashes, and eye pruritus, are consistent with AEs reported in other shorter-term studies. ${ }^{7,14}$ Moreover, as in other studies of bimatoprost ophthalmic solution $0.03 \%$, these AEs rarely led to discontinuation from the study. Only $4 \%$ of patients receiving QD bimatoprost ophthalmic solution $0.03 \%$ discontinued the study or treatment due to conjunctival hyperemia, which was reported by $43.7 \%$ of patients. One limitation of this pooled analysis is that it does not include data for the eyelash hypotrichosis indication.

Common AEs were expected and consistent with the pharmacological mechanisms of bimatoprost. Conjunctival hyperemia is a consequence of prostamide-induced vasodilation, and is typically transient. ${ }^{2,18,19}$ In the recently completed phase III clinical study of bimatoprost ophthalmic solution $0.03 \%$ for treatment of hypotrichosis, the incidence of conjunctival hyperemia was approximately an order of magnitude lower (3.6\% with QD eyelid application versus

Table 4 Cumulative incidence of common AEs reported at months 12, 24, 36, and 48 in the double-masked/open-label extension glaucoma studies with exposure 12-48 months

\begin{tabular}{|c|c|c|c|c|c|c|}
\hline \multirow[t]{3}{*}{ AE } & \multicolumn{6}{|c|}{ Cumulative incidence of AEs, \% } \\
\hline & \multicolumn{4}{|c|}{$\begin{array}{l}\text { QD bimatoprost ophthalmic } \\
\text { solution } 0.03 \%(n=474)\end{array}$} & \multicolumn{2}{|c|}{$\begin{array}{l}\text { BID bimatoprost ophthalmic } \\
\text { solution } 0.03 \%(n=483)\end{array}$} \\
\hline & $\leq 12$ months & $\leq 24$ months & $\leq 36$ months & $\leq 48$ months & $\leq 12$ months & $\leq 24$ months \\
\hline Conjunctival hyperemia & 45.1 & 45.8 & 46.4 & 46.4 & 56.5 & 57.1 \\
\hline Growth of eyelashes & 35.4 & 36.5 & 36.5 & 36.7 & 45.5 & 46.6 \\
\hline Eye pruritus & 13.9 & 14.3 & 14.6 & 14.8 & 16.1 & 16.4 \\
\hline Skin hyperpigmentation & 5.7 & 6.1 & 6.3 & 6.3 & 11.8 & 12.2 \\
\hline Eye irritation & 8.0 & 8.4 & 8.6 & 9.1 & 8.3 & 9.7 \\
\hline Dry eye & 7.8 & 8.2 & 8.9 & 8.9 & 10.1 & 10.8 \\
\hline Hypertrichosis & 8.2 & 8.6 & 8.9 & 8.9 & 9.1 & 9.1 \\
\hline
\end{tabular}

Abbreviations: $A E$, adverse event; $B I D$, twice daily; $Q D$, once daily. 


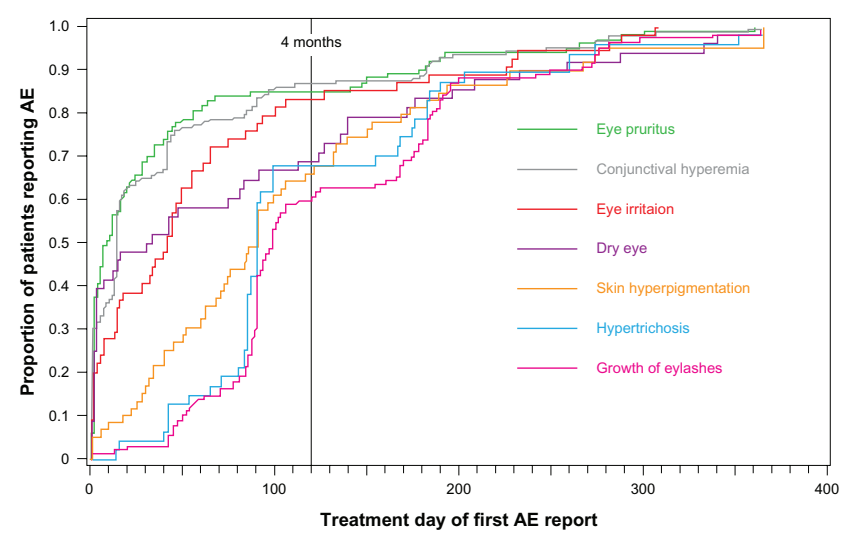

Figure I Temporal onset of common AEs in patients receiving bimatoprost ophthalmic solution $0.03 \%$ QD during the first 12 months of treatment in the six pooled long-term glaucoma studies.

Abbreviation: $\mathrm{AE}$, adverse event.

43.7\% with QD eyedrops) than in this pooled analysis. ${ }^{11}$ This difference may be attributable to the 20-fold (for QD) and 40-fold (for BID) reduction in drug exposure when bimatoprost is applied to the upper eyelid margin in comparison with application as an eyedrop (Pers comm, Allergan, Inc). Furthermore, since the bimatoprost solution is applied to the skin for the hypotrichosis indication and not instilled directly into the eye, the skin barrier may further reduce eye and systemic exposure.

The frequency of iris color change, which appears to be an irreversible side effect associated with prostamides and prostaglandin analogs, was extremely low (0.9\%) among patients receiving QD bimatoprost ophthalmic solution $0.03 \%$ in these glaucoma studies. This rate is consistent with reported rates of $1.1 \%-1.5 \%$ for bimatoprost and $5.1 \%-10.1 \%$ for latanoprost. ${ }^{18}$ Iris color change has not been reported in any clinical trials investigating patients receiving bimatoprost ophthalmic solution $0.03 \%$ for hypotrichosis. ${ }^{11}$

The incidence of skin hyperpigmentation among patients receiving QD bimatoprost ophthalmic solution $0.03 \%$ in the pooled analysis through 48 months was $6.3 \%$ from doublemasked, open-label-extension studies. This side effect is most often limited to the periocular area and appears to be reversible following treatment discontinuation. ${ }^{18}$ The incidence of skin hyperpigmentation reported in a clinical study of bimatoprost ophthalmic solution $0.03 \%$ for eyelash growth was $2.9 \%$ and was not statistically more common than in the vehicle group. ${ }^{18}$

\section{Conclusion}

No unexpected safety signals were identified in this pooled analysis of studies involving continuous bimatoprost ophthalmic solution $0.03 \%$ use for ocular hypertension or glaucoma treatment for up to four years. All AEs reported (incidence $\geq 5 \%$ ) were consistent with those previously encountered in clinical studies of bimatoprost. The most common AE, conjunctival hyperemia, is typically mild, transient, and rarely resulted in treatment discontinuation. Only $4 \%$ of the patients treated QD discontinued due to conjunctival hyperemia, which occurred within the first year of treatment. Based on these six long-term studies in 1409 patients with glaucoma, bimatoprost $0.03 \%$ has a favorable safety and tolerability profile when instilled in the eye. A long-term study to evaluate the effect of topical application of bimatoprost to the eyelid margins on eyelash growth is currently underway.

\section{Acknowledgments}

The authors acknowledge the contribution of the individual study investigators and Allergan employees to the study designs and data analyses. Writing and editorial assistance was provided by Stephen Collins, $\mathrm{PhD}$, of Ogilvy CommonHealth, Parsippany, NJ, USA.

\section{Disclosure}

These studies were supported by Allergan, Inc, Irvine, CA. Funding for writing and editorial support was provided by Allergan, Inc, Irvine, CA. Dr Wirta is an investigator for Allergan. He has received grants for his work. FCB, SK, AMV, EW, and SMW are or were employees of Allergan, Inc at the time of the analysis. This study was previously presented at the 33rd Hawaii Dermatology Seminar, Maui, HI, held on February 7-13, 2009.

\section{References}

1. Lumigan [package insert]. Irvine, CA: Allergan, Inc; 2006.

2. Cracknell KP, Grierson I. Prostaglandin analogues in the anterior eye: Their pressure lowering action and side effects. Exp Eye Res. 2009;88(4): 786-791.

3. Arranz-Marquez E, Teus MA. Prostanoids for the management of glaucoma. Expert Opin Drug Saf. 2008;7(6):801-808.

4. Alexander CL, Miller SJ, Abel SR. Prostaglandin analog treatment of glaucoma and ocular hypertension. Ann Pharmacother. 2002;36(3): 504-511.

5. Brubaker RF. Mechanism of action of bimatoprost (Lumigan). Surv Ophthalmol. 2001;45(Suppl 4):S347-S351.

6. Cohen JS, Gross RL, Cheetham JK, VanDenburgh AM, Bernstein P, Whitcup SM. Two-year double-masked comparison of bimatoprost with timolol in patients with glaucoma or ocular hypertension. Surv Ophthalmol. 2004;49(Suppl 1):S45-S52.

7. Whitcup SM, Cantor LB, VanDenburgh AM, Chen K; for the Bimatoprost Study Group II. A randomised, double masked, multicentre clinical trial comparing bimatoprost and timolol for the treatment of glaucoma and ocular hypertension. Br J Ophthalmol. 2003;87(1): 57-62.

8. Higginbotham EJ, Schuman JS, Goldberg I, et al; for the Bimatoprost Study Groups 1 and 2. One-year, randomized study comparing bimatoprost and timolol in glaucoma and ocular hypertension. Arch Ophthalmol. 2002;120(10):1286-1293. 
9. Williams RD, Cohen JS, Gross RL, Liu C-C, Safyan E, Batoosingh AL; for the Bimatoprost Study Group. Long-term efficacy and safety of bimatoprost for IOP lowering in glaucoma and ocular hypertension: Year 4. Br J Ophthalmol. 2008;92(10):1387-1392.

10. Woodward DF, Liang Y, Krauss AH-P. Prostamides (prostaglandinethanolamides) and their pharmacology. Br J Pharmacol. 2008;153(3): 410-419.

11. Latisse [package insert]. Irvine, CA: Allergan, Inc; 2009.

12. Smith S, Fagien S, Somogyi C, Whitcup SM, Beddingfield FC. Eyelash growth in subjects treated with bimatoprost ophthalmic solution $0.03 \%$; a multicenter, randomized, double-masked, vehicle-controlled, parallel study. Poster presented at the 67th annual meeting of the American Academy of Dermatology, March 6-9, 2009, San Francisco, CA.

13. Law SK. Bimatoprost in the treatment of eyelash hypotrichosis. Clin Ophthalmol. 2010;4:349-358.

14. Brandt JD, VanDenburgh AM, Chen K, Whitcup SM; for the Bimatoprost Study Group 1. Comparison of once- or twice-daily bimatoprost with twice-daily timolol in patients with elevated IOP: A 3-month clinical trial. Ophthalmology. 2001;108(6):1023-1031.
15. Brandt JD, Cantor LB, Katz LJ, Batoosingh AL, Chou C, Bossowska I Bimatoprost/timolol fixed combination: A 3-month double-masked, randomized parallel comparison to its individual components in patients with glaucoma or ocular hypertension. J Glaucoma. 2008;17(3): 211-216.

16. Lewis RA, Gross RL, Sall KN, Schiffman RM, Liu CC, Batoosingh AL; for the Ganfort Investigators Group II. The safety and efficacy of bimatoprost/timolol fixed combination: A 1-year double-masked, randomized parallel comparison to its individual components in patients with glaucoma or ocular hypertension. J Glaucoma. 2009;19(6): 424-426.

17. Katz LJ, Cohen JS, Batoosingh AL, Felix C, Shu V, Schiffman RM. Twelve-month, randomized, controlled trial of bimatoprost $0.01 \%$, $0.0125 \%$, and $0.03 \%$ in patients with glaucoma or ocular hypertension. Am J Ophthalmol. 2010;149(4):66-71.

18. Holló G. The side effects of the prostaglandin analogues. Expert Opin Drug Saf. 2007;6(1):45-52.

19. Chen J, Dinh T, Woodward DF, et al. Bimatoprost: Mechanism of ocular surface hyperemia associated with topical therapy. Cardiovasc Drug Rev. 2005;23(3):231-246.
Clinical Ophthalmology

\section{Publish your work in this journal}

Clinical Ophthalmology is an international, peer-reviewed journal covering all subspecialties within ophthalmology. Key topics include: Optometry; Visual science; Pharmacology and drug therapy in eye diseases; Basic Sciences; Primary and Secondary eye care; Patien Safety and Quality of Care Improvements. This journal is indexed on

Submit your manuscript here: http://www.dovepress.com/clinical-ophthalmology-journal

\section{Dovepress}

PubMed Central and CAS, and is the official journal of The Society of Clinical Ophthalmology (SCO). The manuscript management system is completely online and includes a very quick and fair peer-review system, which is all easy to use. Visit http://www.dovepress.com/ testimonials.php to read real quotes from published authors. 